\title{
PARTIDOS POLITICOS Y DERECHO FUNDAMENTAL DE ASOCIACION. ANOTACIONES CRITICAS A LA STC 48/2003, DE 12 DE MARZO
}

\author{
Josu Iñaki Erkoreka Gervasio
}

Sumario: 1. Introducción. 2. Los postulados del Tribunal Constitucional a propósito de la relación entre los artículos 6 y 22 de la norma fundamental. 3. Observaciones críticas a la Sentencia 48/2003, de 12 de marzo. 4. Observación final.

—Cuando yo utilizo una palabra — aseguró Humpty— esa palabra significa exactamente lo que yo quiero que signifique, ni más ni menos.

- La cuestión consiste en saber — replicó Alicia-, si se puede hacer que una palabra signifique cosas tan diferentes.

- La cuestión — repuso Humpty - consiste en saber quien manda y punto.

Lewis CARroll, Alicia en el país de las maravillas.

\section{Introducción}

Durante la tramitación parlamentaria de la Ley Orgánica 6/2002, de 27 de junio, de Partidos Políticos [en adelante LOPP], no faltaron voces - procedentes tanto del mundo político como del académico e incluso del judicial - que cuestionaron vivamente la constitucionalidad de algunos de sus principales contenidos. Curiosamente, sin embargo, una vez aprobada la norma e impugnada ante el Tribunal Constitucional [en adelante TC] ninguna de ellas expresó, al menos públicamente, la más mínima esperanza de que el alto tribunal pudiese llegar a estimar, ni tan siquiera en parte, las alegaciones planteadas por la actora en su recurso. La persuasión de que, en las circunstancias en las que se había producido el debate sobre la LOPP, no era concebible un posicionamiento del TC — de este TC - que osara desautorizar los poderosos apoyos sociales, políticos y hasta mediáticos con los que ésta había concluido el trámite parlamentario, gozaba de una implantación tal que, nadie, ni entre los convencidos de la inconstitucionalidad de la norma, ni, por supuesto, entre los más firmes defensores de lo contrario, se 
arriesgó a aventurar la posibilidad de que el pleito fuese a concluir con un pronunciamiento - aun parcialmente - favorable a la parte actora.

Esta generalizada convicción se tradujo en absoluta certeza cuando, en un modélico gesto de imparcialidad, el presidente del alto tribunal hizo las declaraciones que provocaron el incidente de recusación resuelto por el Auto 61/20003, de 19 de febrero. Interrogado sobre si «la eventual ilegalización de Batasuna va a superar el trámite del Constitucional», el presidente del TC -investido, no se olvide, con voto de calidad y, además, ponente del caso- expresó su confianza en que «lo hagamos lo mejor que sepamos», a efectos de conseguir «una ilega...» de la formación citada.

La afortunada intervención del presidente contribuyó decisivamente a iluminar el panorama. Entre otras cosas, dejó claro que el recurso de inconstitucionalidad interpuesto contra la LOPP no iba a prosperar porque, al margen de otras consideraciones, el tribunal encargado de resolverlo se iba a empeñar en «hacerlo lo mejor que supiera» para que eso no ocurriera. Así, pues, si alguien, en algún momento, había llegado a abrigar alguna duda al respecto, se encargaba de disipársela nada menos que el mismísimo presidente del TC y ponente del caso.

Tras estas declaraciones, que desvelaron definitivamente cuál iba a ser el sentido de la sentencia que había de dictar el TC, él único interés que ésta suscitaba tenía que ver con el esfuerzo argumental que sus redactores fueran a desarrollar para alcanzar la meta fijada. Si el tribunal, según confesión de su propio presidente, lo iba a hacer «lo mejor que supiera» para alcanzar la consecución de un objetivo que parecía ya claramente establecido - la «ilega...» de Batasuna-, sólo quedaba por descubrir cuál era la forma que «mejor sabía» el alto tribunal para alcanzar aquel propósito. $\mathrm{O}$, dicho en otros términos, sólo restaba comprobar la capacidad - y, sobre todo, la creatividad - del alto tribunal, para argumentar en Derecho con objeto de construir una fundamentación jurídica que sirva de soporte a una decisión adoptada con arreglo a parámetros extrajurídicos.

La tarea, hay que reconocerlo, no estaba exenta de dificultades porque, como a continuación veremos, los pronunciamientos que hasta entonces había dictado el tribunal en relación con el modo en el que ha de abordarse la interpretación conjunta y sistemática de los arts. 6 y 22 de la norma fundamental, no parecían dejar vía franca al reconocimiento de supuestos de ilegalización de partidos políticos distintos a los que pudieran asociarse al incumplimiento del deber - expresamente impuesto por el art. $6 \mathrm{CE}$ - de contar con «una estructura interna y un funcionamiento de carácter democrático»y, en su caso, a la previsión 
contenida en el apartado $2 .^{\circ}$ del art. 22 CE que declara ilegales «las asociaciones que persigan fines o utilicen medios tipificados como delitos». Pero el presidente del alto tribunal había prometido que lo haría «lo mejor que supiera» y nadie ponía en duda de que sabría superar los escollos con elegancia. Al fin y al cabo, basta un cierto dominio de los recursos argumentales reconocidos como válidos en el mundo del Derecho para que el operador jurídico pueda desarrollar exégesis prácticamente libérrimas de un texto tan henchido de ambigüedades como el constitucional. Como cualquier jurista avezado sabe, en semejantes condiciones, una adecuada aplicación de argumentos opuestos, permite al intérprete alcanzar, sobre unos mismos presupuestos fácticos, conclusiones radicalmente distintas. Sólo es cuestión de destreza en el empleo de la argumentación jurídica, algo que, evidentemente, no puede negarse al TC.

El presente trabajo se propone desarrollar un análisis crítico sobre una parte del esquema argumental utilizado por el TC para fundamentar la resolución dictada para resolver el recurso ${ }^{1}$. Más concretamente, la parte en la que aborda la exégesis conjunta de los dos citados artículos -el 6 y el 22- de la norma constitucional. En este punto, como veremos, el TC «supo hacerlo» bastante bien. Cumplió su cometido con una innegable lucidez. Pero, como también veremos, para alcanzar su propósito, se vio obligado a violentar algunos de los postulados que en los años anteriores había venido sentando en la materia y a despreciar, incomprensiblemente, la conveniencia de indagar en el alcance y sentido de algunos preceptos constitucionales de directa aplicación al caso. Pequeños pelos en la gatera que, sin embargo, sólo una lectura atenta de la sentencia y de sus antecedentes permite poner de relieve.

\section{Los postulados del Tribunal Constitucional a propósito de la relación entre los artículos 6 y 22 de la norma fundamental}

Con anterioridad a la sentencia de 12 de marzo de 2003, el TC dispuso de tres ocasiones para pronunciarse sobre la relación entre los artículos 6 y 22 de la Constitución. En las sentencias 3/1981, de 2 de febrero y 85/1986, de 25 de junio, lo hizo con motivo de la creación de sendos partidos políticos -el Partido Comunista de España (Marxista-Leninista) y el Partido Comunista de Aragón-, sobre cuyo proceso

1 STC /2003, de 12 de marzo. 
de constitución, la Administración pública había pretendido ejercer un control que el alto tribunal consideró incompatible con la naturaleza inequívocamente asociativa de los partidos. En ambos casos, el TC sostuvo, básicamente que, por encima de las peculiaridades que singularizan a los partidos políticos con respecto a las asociaciones de régimen común -el art. 6 establece específicamente para los partidos que «... su creación [...] [es libre] dentro del respeto a la Constitución y a la ley-, a su proceso de constitución le es directa y plenamente aplicable lo dispuesto en el art. 22-3 CE, cuando establece que la obligatoria inscripción de las asociaciones en un registro público, ha de producirse «... a los solos efectos de publicidad».

El Abogado del Estado se esforzó en soslayar la aplicación del art. $22 \mathrm{CE}$, argumentando que «en todo caso, el artículo fundamental de la Constitución sobre partidos políticos sería el 6 y no el 22» [STC 3/1981, antecedente 3]. Pero el alto tribunal estimó que cualesquiera que fuesen las peculiaridades que aquél precepto atribuyese a los partidos, tales peculiaridades no podían impedir la aplicación del art. 22.3 de la norma fundamental a unas entidades que, ante todo y sobre todo, eran auténticas asociaciones. En otras palabras, que el art. $22 \mathrm{CE}$ es tan nuclear a la hora de fijar el régimen constitucional de los partidos políticos, como el propio art. 6; de suerte que los mandatos de éste, no pueden invocarse como razón obstativa para la aplicación de aquél.

Por su parte, la sentencia 56/1995, de 6 de marzo, conoció - y resolvió- un recurso de amparo que, entre otros aspectos, planteaba el de elucidar el alcance, contenido y efectos del inciso final del art. $6 \mathrm{CE}$ que establece con respecto a los partidos políticos que, «Su estructura interna y funcionamiento deberán ser democráticos». Pese a las notables diferencias que este supuesto ofrecía en relación con los dos anteriores - nótese que, mientras en aquellos se trataba de armonizar un mandato explícito contenido en el art. 22.3 CE, con una previsión genérica sobre la libertad de creación de los partidos políticos incluida en el art. 6 de la misma norma legal, lo que en este se planteaba era, más bien lo contrario, esto es, conjugar un mandato concreto y expreso del art. 6 con la potestad de autoorganización, que es un contenido genéricamente incluido por la jurisprudencia constitucional en el derecho de asociación- el TC tiende a adoptar una posición similar. Como en las sentencias precedentes, se esfuerza en integrar el mandato expreso del art. 6, dentro del marco del art. 22, reconociendo a éste un valor prevalente en el régimen constitucional de los partidos políticos; un valor prevalente que, en caso de contradicción, sólo puede ceder ante expresas e inequívocas previsiones de aquél, en un esfuerzo exegético que 
debe perseguir una interpretación «conjunta y sistemática [de ambos preceptos], sin separaciones artificiosas».

Veamos los principales postulados que el TC ha sostenido en estas tres sentencias.

\subsection{Un partido político es una forma particular de asociación}

Una de las primeras cuestiones a la que tuvo que dar respuesta el TC en su andadura como institución, fue la de definir la relación de los partidos políticos con las entidades asociativas a las que se refiere el art. 22 de la carta magna y, consecuentemente, la de pronunciarse sobre su eventual incardinación en el reforzado ámbito de protección que la norma fundamental contempla para los derechos fundamentales como el de asociación, sistemáticamente ubicados en la sección $1 .^{a}$ del capitulo segundo, del título I de la Constitución.

Ya en su temprana sentencia 3/1981, de 2 de febrero, el alto tribunal se enfrentó a esta cardinal cuestión, preguntándose si «el derecho a crear partidos políticos es susceptible de amparo en virtud del artículo 22 de la CE que consagra el derecho de asociación». La respuesta fue tan clara como contundente. «Un partido - afirmó el tribunal- es una forma particular de asociación y el citado artículo 22 no excluye las asociaciones que tengan una finalidad política, ni hay base alguna en él para deducir tal exclusión». Desde entonces, este postulado ha constituido un elemento nuclear de la jurisprudencia del alto tribunal sobre los partidos políticos. Estos, ha llegado a proclamar el tribunal, son «sin, duda, asociaciones», si bien es verdad que se trata de entidades asociativas «que poseen unas características e incluso una naturaleza propias y específicas» [STC 56/1995, de 6 de marzo, f. J. $\left.3 .^{\circ}\right]$.

La consecuencia principal del hecho de que los partidos políticos, en tanto que asociaciones, se incluyan bajo la protección del artículo $22 \mathrm{CE}$, es la de que el contenido de este precepto, «... conforma el núcleo básico del régimen constitucional de los partidos políticos» [STC 85/1986, f. J. 2; STC 56/1995, f. J. 3. ${ }^{\circ}$ ]. El art. 22 CE, no constituye, como se ve, una mera referencia jurídica a tener en cuenta por el operador jurídico. Constituye nada menos que «el núcleo básico» de su régimen constitucional. Más específica y contundentemente aún si cabe, el alto tribunal ha llegado a sostener que «... las previsiones contenidas en los apartados 2 y siguientes del artículo 22, en tanto que "garantía común" del derecho de asociación [STC 67/1985], son aplicables a todo tipo de asociaciones, incluidos los partidos políticos» [STC 56/1995, de 6 de marzo, f. J. $3 .^{\circ}$ ]. 
Los partidos políticos son, pues, ante todo y principalmente, asociaciones. Entidades asociativas con una «forma particular» o, si se prefiere, con «unas características e incluso una naturaleza propia y específica», pero «sin duda, asociaciones». Así lo ha venido postulando sin fisuras el TC. Es más, son - por si alguien albergara alguna dudaasociaciones constituidas al amparo del art. $22 \mathrm{CE}$ y a las que, en lógica consecuencia, les son de aplicación «las previsiones contenidas en los apartados 2 y siguientes» de este precepto que, conforman así, «el núcleo básico» de su régimen constitucional.

Como después veremos, esta opción del alto tribunal por erigir el art. $22 \mathrm{CE}$ en auténtico eje del régimen constitucional de los partidos políticos resulta lógica y razonable en el contexto normativo de la carta magna. El de asociación es un derecho fundamental imprescindible en todo régimen democrático - sin libre derecho de asociación no puede concebirse una sociedad democrática que merezca, de verdad, este calificativo-, mientras que la mención específica que el art. 6 hace a los partidos políticos — que entronca con una tendencia impuesta por el constitucionalismo europeo de posguerra - no era - ni es - indispensable para que la Constitución de 1978 fuera identificada como auténticamente democrática. De hecho, ha habido y aún hay constituciones inequívocamente democráticas que carecen de un precepto equivalente al $6 .^{\circ}$ de la vigente norma fundamental española.

Por otra parte, el art. $6 \mathrm{CE}$ - un precepto descriptivo donde los haya-, está dotado de un exiguo contenido normativo. Basta una superficial lectura de sus diferentes pasajes - en los que las formas verbales indicativas prevalecen ostensiblemente sobre las formas imperativas características del lenguaje normativo- para reparar en esta circunstancia. Pretender que sus limitados mandatos agoten la disciplina constitucional de los partidos políticos, equivale a privar a éstos de un régimen jurídico-constitucional mínimamente vertebrado. Resulta, por ello, aconsejable, completar sus previsiones con otras de rango - también - constitucional, que permitan definir con una mayor nitidez la naturaleza y las condiciones de creación y funcionamiento de los partidos políticos. Y en este contexto, el precepto constitucional que proclama el derecho de asociación, constituye un asidero que, evidentemente, el TC no podía soslayar.

En fin, tampoco puede olvidarse que, además de las razones anteriores, el derecho de asociación es el marco jurídico en el que tradicionalmente se ha inscrito el régimen de los partidos políticos. Sin necesidad de citar ahora los abundantes ejemplos del derecho histórico y del comparado que avalan esta afirmación, baste recordar el esfuerzo desarrollado por el Tribunal Europeo de Derechos Humanos - muy especial- 
mente desde la sentencia 752/1998, de 30 de enero, caso Partido Comunista Unificado de Turquía contra Turquía - para situar a los partidos políticos en el ámbito de aplicación del art. 11 del Convenio Europeo, que consagra el derecho de asociación. En el citado y en posteriores casos, los gobiernos demandados se han venido oponiendo a esta incardinación, apelando, entre otras razones, al carácter cuasi-institucional que revisten los partidos políticos en las modernas democracias pluralistas. Para ello, se han apoyado en el hecho de que, en algunos estados europeos - entre los que se sitúa el español— los partidos políticos reciben un tratamiento constitucional formalmente diferenciado del previsto para la libertad de asociación; un tratamiento que los sitúa «en la parte relativa a las estructuras constitucionales fundamentales», sustrayéndolos del régimen previsto para las asociaciones. Una tesis, como se ve, semejante a la que el Abogado del Estado defendió sin éxito en la STC 3/1981, de 2 de febrero, cuando, al referirse a los partidos políticos, sostuvo la absoluta prevalencia del art. 6 sobre el art. 22 de la norma fundamental. Pero el alto tribunal europeo no ha dudado un ápice en ignorar esta visión institucional de los partidos políticos, para afirmar su naturaleza inequívocamente asociativa y declarar, en consecuencia, la plena aplicación a los mismos, de la disciplina convencional concerniente al derecho fundamental de asociación.

Parece claro, pues, que, por las razones expuestas, el artículo $22 \mathrm{CE}$ estaba llamado a desempeñar una función central en el régimen constitucional de los partidos políticos. Y, como hemos visto, el TC descubrió y afirmó esta tesis desde su más temprana jurisprudencia.

\subsection{Los partidos políticos son asociaciones de «relevancia constitucional», cualificadas por las funciones que tienen encomendadas}

La naturaleza inequívocamente asociativa que el TC reconoce a los partidos políticos, no oculta, sin embargo, su evidente singularidad. Ya hemos visto que el alto tribunal los ha calificado de «formas particulares de asociación». Pero, ¿en qué consiste esta particularidad?

Según el TC, la mención específica del artículo 6 CE convierte a los partidos políticos en asociaciones de «relevancia constitucional» [STC 3/1981, f. J. 1. $^{\circ}$ ]; una nota, en principio, exclusivamente formal - en la medida en que resulta de la mera existencia de una referencia nominativa y singularizada en el articulado de la Constitución-que sirve para distinguir a los partidos políticos de las asociaciones ordinarias, las cuales, quedan así, configuradas negativamente, como aquellas que no gozan de más cobertura constitucional que la que les proporciona el art. 22 de la carta magna. 
Pero el de la «relevancia constitucional» no es un rasgo privativo de los partidos políticos. Antes al contrario, se trata de una característica que los partidos comparten con otras formas particulares de asociación que son, igualmente, objeto de una cita específica por parte de la norma fundamental. Piénsese en los sindicatos de trabajadores y en las asociaciones empresariales (art. $7 \mathrm{CE})^{2}$ o, en otra dimensión, en los colegios profesionales (art. $36 \mathrm{CE}$ ) y en las organizaciones profesionales (art. $52 \mathrm{CE}$ ) que son, también, entes de base asociativa nominativamente citados por la norma constitucional. Por unas u otras razones, el constituyente ha considerado que, sin perder su básica e incuestionable naturaleza asociativa, todos ellos merecían una especial consideración por parte de la norma fundamental. Una especial consideración que, evidentemente, no en todos los casos reviste igual alcance, sentido e importancia. Basta reparar en la diferente ubicación sistemática que las diferentes referencias ocupan dentro del articulado constitucional.

Por lo que se refiere a los partidos políticos, que son los que aquí interesan, la «relevancia constitucional» que tan enfáticamente denota el máximo intérprete de la carta magna, viene justificada, según postula el propio alto tribunal, «por la importancia decisiva que esas organizaciones tienen en las modernas democracias pluralistas» [STC 3/1981, f. J. $1^{\circ} .^{\circ}$. Por ello, la distinción que les concede el texto constitucional es, también, del máximo nivel. Así lo destaca el propio tribunal cuando resalta la relevancia de su emplazamiento sistemático:

«La colocación sistemática de este precepto expresa la importancia que se reconoce a los partidos políticos dentro del sistema constitucional, y la protección que de su existencia y de sus funciones se hace, no sólo desde la dimensión individual del derecho a constituirlos y a participar activamente en ellos, sino también en función de la existencia del sistema de partidos como base esencial para la actuación del pluralismo político» [STC 85/1986, f. J. 2].

El fragmento transcrito nos aproxima, por otro lado, a lo que podemos denominar la vertiente institucional de los partidos políticos, es decir, su decisiva contribución a la conformación del sistema de partidos, «como base esencial para la actuación del pluralismo político».

Aunque, como hemos visto, el TC tiende a hacer prevalecer la consideración de los partidos políticos como una concreta expresión

${ }^{2}$ El Tribunal Constitucional los califica como de «formaciones sociales con relevancia constitucional» [STC 18/1984, de 7 de enero]. 
del derecho de asociación, lo cierto es que tampoco desprecia su vertiente institucional, si bien es verdad que, de facto, atribuye a ésta una operatividad jurídica notablemente inferior. En el fragmento transcrito, el alto tribunal se esfuerza en observar que la norma fundamental contempla a los partidos políticos, «no sólo» desde la dimensión individual del derecho a constituirlos y a participar activamente en ellos, «sino también» en función de la existencia del sistema de partidos como base esencial para la actuación del pluralismo político. Pero lo cierto es que la vertiente institucional queda reducida, en las sentencias del TC, a poco más que una afirmación retórica, sin apenas transcendencia jurídica. Y, en cualquier caso, a una afirmación que en nada empece la plena operatividad del art. $22 \mathrm{CE}$.

\subsection{La «relevancia constitucional» de los partidos políticos no altera su esencial naturaleza asociativa. Sólo justifica la existencia de «normas específicas»}

Según hemos visto en los epígrafes anteriores, desde su primera sentencia sobre el tema, el TC ha venido sosteniendo que las singulares reglas que el art. $6 \mathrm{CE}$ establece para los partidos políticos, no desvirtúan su naturaleza esencialmente asociativa. De las previsiones específicas que contiene este artículo en relación con la estructura interna y el funcionamiento necesariamente democráticos de los partidos políticos — ha sentado el alto tribunal—, «no se deriva que los ciudadanos no puedan invocar el derecho general de asociación para constituirlos, y que no puedan acudir en amparo a este Tribunal Constitucional, por violación del artículo 22 si entienden que se vulnera tal derecho». Pese a los específicos mandatos del artículo $6 \mathrm{CE}$, los partidos siguen siendo, a todos los efectos, asociaciones constituidas al amparo del artículo 22 de la norma fundamental y, por tanto, les son de aplicación los diferentes apartados de este precepto. En este punto el alto tribunal ha sido contundente: «El hecho de que los partidos políticos figuren en el titulo preliminar de la Constitución responde únicamente a la posición y al relieve constitucional que los constituyentes quisieron atribuirles, pero eso no significa que al crear y participar en un partido se esté ejerciendo un derecho distinto del derecho de asociación» [STC 56/1995, de 6 de marzo]. La cualificación que la Constitución reconoce a los partidos políticos no les convierte en órganos del Estado, ni en titulares del poder público. Los partidos, ha señalado el TC, «... no son órganos del Estado [...] [y] la trascendencia política de sus funciones [...] no altera su naturaleza [asociativa]» [STC 1/1983, de 2 de febrero, FJ 3] 
¿Cuál es, entonces, la incidencia efectiva de su singular naturaleza en el régimen jurídico de los partidos políticos? Según el alto tribunal, de los mandatos del art. 6 CE se deriva

«... la posibilidad de que existan normas específicas para esas asociaciones de relevancia constitucional que, en todo caso, deberán respetar la Constitución y, particularmente, los derechos fundamentales y libertades públicas consagrados en ella» [STC 3/1981, f. J. 1.º].

La lectura del pasaje transcrito suscita de inmediato una pluralidad de interrogantes. Algunas tienen que ver con la virtualidad jurídica de las normas específicas que, según el alto tribunal, pueden dictarse para regular estas asociaciones de relevancia constitucional. Otras, no menos importantes, afectan al inexorable límite que el órgano judicial impone a estas normas cuando afirma que «en todo caso, deberán respetar la Constitución y, particularmente, los derechos fundamentales y libertades públicas consagrados en ella».

Analicemos por separado estos dos órdenes de cuestiones.

La primera de las interrogantes planteadas apunta al sentido, alcance y límites de las normas específicas que el legislador puede establecer para los partidos políticos. ¿Cuál es su contenido jurídicamente posible?; ¿pueden suplantar sin límites a las normas que disciplinan con carácter general el derecho de asociación, o tan sólo pueden desarrollarlas o completarlas, teniendo, en todo caso que respetarlas?

Señalemos en primero lugar que es el propio artículo 6 de la carta magna el ejemplo más palpable de la posibilidad constitucional de dictar normas específicas para esa forma particular de asociación que son los partidos políticos. Al establecer directamente una serie de reglas singulares que sólo resultan de aplicación a los partidos, este precepto sienta claramente tal posibilidad, elevándola, además, al máximo rango jurídico. Así pues, las principales normas específicas aplicables los partidos políticos en tanto que asociaciones de relevancia constitucional, son las recogidas en el artículo $6 \mathrm{CE}$. A ellas se refiere el TC cuando afirma que, en este precepto «...se han establecido unas condiciones específicas para los partidos políticos en relación al respeto al orden constitucional y a su estructuración interna de carácter democrático» [STC 85/1986, f. J. 2].

Pero el alto tribunal no afirma en el párrafo transcrito que las especiales condiciones fijadas por el art. $6 \mathrm{CE}$ revistan una potencialidad infinita o habiliten al legislador para diversificar sin límite el régimen de los partidos políticos con respecto al de las asociaciones ordinarias. Para el TC, en el art. 6 de la norma fundamental, tan sólo constituyen normas o «condiciones específicas» de los partidos políticos, las que 
guardan relación con el «respeto [debido] al orden constitucional» y las que se refieren «a su estructuración interna de carácter democrático». La especificidad normativa de estas formas particulares de asociación se agota, pues, en lo que el artículo $6 \mathrm{CE}$ establece a propósito del respeto al orden constitucional y de su estructura y funcionamiento democráticos. Desde luego nada tiene que ver con el régimen de creación de los partidos políticos, pues ésta - afirma el tribunal-, no está «sometida constitucionalmente a límites más estrictos que los de las demás asociaciones» [STC 85/1986, f. J. 2] y tampoco atañe a su actividad. Así lo ha sostenido el propio TC:

«De la lectura conjunta del artículo $6 .^{\circ}$ de la Constitución Española en conexión con el artículo 22 de la misma, resulta una protección reforzada de la libertad de partidos políticos que debe entenderse afecta no sólo a la actividad de los mismos, sino a su propia creación» [STC 85/1986, f. J. 2].

Por otra parte, el alto tribunal ha precisado que estas condiciones específicas que el art. $6 \mathrm{CE}$ ha establecido para con los partidos políticos «... se añaden y no sustituyen a las del artículo 22, por situarse en un nivel diferente» [STC 85/1986, f. J. 2]. El alto tribunal observa a este respecto que:

«La Constitución, en su deseo de asegurar el máximo de libertad e independencia de los partidos, los somete al régimen privado de las asociaciones, que permite y asegura el menor grado de control y de intervención estatal sobre los mismos. La disciplina constitucional en esta materia, tomada en su sustancia, se ha articulado sobre el reconocimiento de un derecho subjetivo público de los ciudadanos a constituir, bajo la forma jurídica de asociaciones, partidos políticos; con ello se reconoce y legitima la existencia de los partidos y se garantiza su existencia y su subsistencia. El partido en su creación, en su organización y en su funcionamiento, se deja a la voluntad de los asociados fuera de cualquier control administrativo, sin perjuicio de la exigencia constitucional del cumplimiento de determinadas pautas en su estructura, actuación y fines [...] Del contexto del propio precepto [art. $22 \mathrm{CE}$ ] se deriva, además, que los instrumentos para garantizar que los partidos se ajusten a la idea que de éstos tiene la Constitución en cuanto a su sujeción al orden constitucional, su respeto de la legalidad, su estructura democrática y los demás requisitos generales que se exigen a todas las asociaciones, han de centrarse fundamentalmente en el momento de la actuación de éstos y por medio de un control judicial. Se trata además y, en todo caso, de límites marginales que parten de, y presuponen una amplísima libertad de constitución y de actuación de partidos políticos» [STC 85/1986, f. J. 2]. 
Como puede verse, la atribución a los partidos políticos de una naturaleza inequívocamente asociativa, ha servido al TC para declarar la plena aplicación a los mismos de los dictados del art. 22 CE. Una aplicación que sólo puede limitar el art. 6 CE en aquéllos ámbitos en los que establece previsiones concretas y específicas para los partidos políticos, es decir, en lo que se refiere «al respeto al orden constitucional y a su estructuración interna de carácter democrático» [STC 85/1986, f. J. 2]. Las especificidades normativas de los partidos no pueden extenderse a otros aspectos, porque son éstos - y sólo éstos- los únicos que el alto tribunal considera como sus «condiciones específicas». Unas condiciones que, por otras parte, no suplantan a las del art. 22. No las desplazan, ni impiden su directa y plena aplicación. Según el TC, «se añaden» a las mismas, pero «no [las] sustituyen».

Por lo demás, dice el TC que el art. 6 no hace sino «reforzar», para los partidos políticos, el régimen de libertad previsto en el art. 22. Un reforzamiento que puede tener alguna limitación en lo que se refiere a la estructura interna de los partidos, pero que se hace especialmente perceptible en su creación y su actividad. Su función constitucional no consiste, pues, en limitar la libertad de asociación proclamada en el art. 22, sino en reforzarla. En virtud del art. 6, la creación y la actividad de los partidos políticos gozan, así, de una libertad «reforzada», en relación con las asociaciones de régimen común. Un dato que, lógicamente, el legislador ordinario no puede desconocer.

\subsection{En todo caso, las «normas específicas» de los partidos políticos han de respetar los derechos fundamentales y libertades públicos consagrados en la Constitución}

El alto tribunal ha sostenido además que, las normas específicas que el legislador pueda dictar en relación con los partidos políticos, «en todo caso, deberán respetar la Constitución y, particularmente, los derechos fundamentales y libertades públicas consagrados en ella» [STC 3/1981, f. J. $1^{\circ}{ }^{\circ}$. Los derechos fundamentales se erigen, así, en un nuevo límite para la diversificación normativa que el art. $6 \mathrm{CE}$ permite establecer para los partidos políticos. De suerte que, el legislador no sólo habrá de cuidar que las normas específicas que dicte para los partidos políticos se circunscriben a los concretos ámbitos en los que el citado art. $6 \mathrm{CE}$ lo permite de modo expreso y persiguen «reforzar» el régimen de libertad establecido con carácter general para las asociaciones de régimen común. No sólo habrá de cuidar de que tales especialidades normativas se configuren con vocación de ser añadidas a los 
preceptos del art. $22 \mathrm{CE}$ y no de sustituirlos. Al margen de todo ello, deberá procurar también que no vulneren el régimen constitucional de los derechos fundamentales.

Esta nueva limitación nos reenvía al art. $22 \mathrm{CE}$, que proclama y regula uno de los principales derechos fundamentales. Si las normas específicas de los partidos políticos han de respetar «... la Constitución y, particularmente, los derechos fundamentales y libertades públicas consagrados en ella», parece evidente que, entre otros, y muy principalmente, habrá de respetar, también, el derecho fundamental de asociación, y hacerlo, además, en los concretos términos en los que viene reconocido por la norma constitucional, lo que obliga a tomar en consideración sus cinco apartados.

\section{Observaciones críticas a la Sentencia 48/2003, de 12 de marzo}

Las consideraciones incluidas en el epígrafe anterior, resumen algunas de las tesis que había venido sentando el TC en relación con el asunto que debía afrontar en su sentencia 48/2003, de 12 de marzo. Uno de los principales aspectos de la norma impugnada que - al menos aparentemente- chocaban con estas tesis, era la aprobación de unas reglas, de exclusiva aplicación a los partidos políticos, que permitían la declaración de ilegalidad de un partido en supuestos distintos a los previstos para el conjunto de las asociaciones en el art. 22.2 CE. Se trataba de una especialidad normativa que, prima facie, ni se situaba en el ámbito al que, según había dicho el TC, deben circunscribirse las especialidades normativas a las que da cobertura el art. $6 \mathrm{CE}$ para los partidos políticos, esto es, en lo concerniente «al respeto al orden constitucional y a su estructuración interna de carácter democrático» [STC 85/1986, f. J. 2], ni parecían respetar las restantes limitaciones impuestas, también, por el TC, para la diversificación normativa de los partidos políticos: El respeto al art. $22 \mathrm{CE}$, a cuyas prescripciones «se añaden», pero «no [las] sustituyen» y al conjunto de los derechos fundamentales y libertades públicas «consagrados» en la norma fundamental. En fin, tampoco parecía que se propusiese, precisamente, «reforzar» para los partidos políticos, el régimen de libertad previsto en el art. 22.

Ante esta situación, el cuestionamiento resultaba insoslayable: ¿Era, la norma aprobada, constitucionalmente posible?; ¿hasta qué punto las reglas específicas dictadas en relación con la ilegalización de los partidos políticos respetaban las pautas sentadas en la materia por el TC? Veamos cómo afronta el alto tribunal estas cuestiones. 


\subsection{Lo que el TC erige en la «primera cuestión» a dilucidar, es un asunto ya resuelto por el alto tribunal, que ni tan siquiera es objeto de discusión por las partes}

El TC no comienza su argumentación con buen pie. Da inicio al razonamiento sobre el que construye la fundamentación de la sentencia, afirmando que «... la primera de las cuestiones a dilucidar en este proceso es si la regulación constitucional de los partidos políticos admite o no en nuestro ordenamiento, un régimen legal específico y distinto del que es propio de las asociaciones. En otras palabras, si los partidos, en tanto que especie del género asociación, no admiten más límites y controles que los previstos en la Constitución para las asociaciones (art. $22 \mathrm{CE}$ ) o si su reconocimiento constitucional en los términos del art. $6 \mathrm{CE}$ implica la existencia de límites y condiciones adicionales» [FJ. 5].

Basta una superficial lectura de los antecedentes de la sentencia para reparar en que este planteamiento inicial del que parte el alto tribunal es claramente falaz. Y lo es, sobre todo - haciendo abstracción ahora del hecho de que la cuestión que el tribunal eleva a la categoría de «primera» a dilucidar, estuviera ya básicamente resuelta por el propio órgano judicial en sentencias anteriores- porque ninguna de las partes enfrentadas en el proceso había llegado a sostener que la regulación constitucional de los partidos políticos excluyera la posibilidad de dotarles de un régimen legal específico y distinto del previsto con carácter general para las asociaciones. Es más, ni tan siquiera llegaron a cuestionar la posibilidad de que, partiendo de una regulación común, los partidos se viesen sujetos a más límites y controles que los previstos en el art. $22 \mathrm{CE}$ para la generalidad de las asociaciones. De hecho, la parte recurrente había reconocido expresamente en sus alegaciones que, en virtud de lo dispuesto en el art. $6 \mathrm{CE}$, los partidos políticos están sujetos a unas limitaciones específicas, relacionadas con su estructura interna y su funcionamiento, que no afectan al conjunto de las asociaciones. Parece claro, pues, que no era esta una cuestión controvertida.

Lo que sí ponía en duda la parte actora —aunque de ello no se haga eco el alto tribunal - era la legitimidad constitucional de un tipo muy concreto de límites y controles legales: De aquellos límites y controles legales que, sin contar con un apoyo claro y expreso en el art. $6 \mathrm{CE}$, vulneran abiertamente lo dispuesto en el art. $22 \mathrm{CE}$ y, especialmente, lo previsto en su apartado $2 .^{\circ}$, que no contempla más asociaciones ilegales que aquellas «que persigan fines o utilicen medios tipificados como delito». Y al cuestionar la constitucionalidad de este tipo de límites y controles - sin amparo directo en el art. 6 y abiertamente contrarios al 
art. 22-, la parte recurrente no hacía sino situarse en la senda trazada por los postulados que el propio TC había venido defendiendo en relación con el modo en el que ha de abordarse la interpretación sistemática de estos dos preceptos de la norma fundamental. Recuérdese que en sus pronunciamientos anteriores, el alto tribunal había hecho afirmaciones como la de que el art. $22 \mathrm{CE}$ constituye «el núcleo básico del régimen constitucional de los partidos políticos» [STC 85/1986, f. J. 2; STC 56/1995, f. J. $3 .^{\circ}$; ; que «...las previsiones contenidas en los apartados 2 y siguientes del artículo 22, en tanto que "garantía común" del derecho de asociación [STC 67/1985], son aplicables a todo tipo de asociaciones, incluidos los partidos políticos» [STC 56/1995, de 6 de marzo, f. J. $3 .^{\circ}$ ] o que las normas específicas que pueden dictarse para los partidos políticos en virtud de su caracterización como asociaciones de relevancia constitucional, «en todo caso, deberán respetar la Constitución $\mathrm{y}$, particularmente, los derechos fundamentales y libertades públicas consagrados en ella» [STC 3/1981, f. J. 1. $^{\circ}$ ]; de entre los que destaca de manera muy especial, el derecho fundamental de asociación.

Si el párrafo $2 .^{\circ}$ del art. $22 \mathrm{CE}$ - que, como hemos visto, el propio TC ha caracterizado como parte del «núcleo básico del régimen constitucional de los partidos políticos», "garantía común del derecho de asociación [...] aplicable a todas las asociaciones, incluidos los partidos políticos» y límite que, «en todo caso» habrán de respetar las especialidades normativas que el legislador, al amparo del art. $6 \mathrm{CE}$, establezca en relación con los partidos políticos- configura un régimen de libertad de asociación en el que no se contemplan más asociaciones ilegales que aquellas «que persigan fines o utilicen medios tipificados como delito», ¿qué más lógico que preguntarse si la Constitución permite establecer, por vía legal, causas y cauces de ilegalización de partidos políticos distintos a los penales?

Es más. En relación con el juego combinado de los artículos 6 y 22 de la norma fundamental, el alto tribunal había postulado, también, que estos dos preceptos «deben interpretarse conjunta y sistemáticamente sin separaciones artificiosas» [56/1995, f. J. 3. ${ }^{\circ}$; ; lo que le había servido para rechazar lecturas favorables a su mutua neutralización y a integrar armónicamente las obligaciones que el art. 6 impone expresa y singularmente a los partidos políticos — como la que dispone que su estructura interna y su funcionamiento deberán ser democráticos-, en el cuadro de facultades que integran el derecho de asociación. Se trataba, como se ve, de que, en ningún caso, la aplicación de uno de los dos preceptos invalidase radicalmente el otro. Su compatibilidad había de procurarse, sin estridencias; sin que la pretensión de aplicar uno de ellos provocase la total inaplicación del otro. 
Pero, extrañamente, en la sentencia de 12 de marzo de 2003, el TC ignora todas estas precisiones que él mismo había formulado en ocasiones precedentes y que tan útiles podían resultarle para la resolución del asunto. Y en lugar de tomarlas en consideración, como cabia esperar de un tribunal que aspira a guardar una mínima coherencia con sus pronunciamientos anteriores, se empeña en dar un paso atrás, planteando como nuclear una cuestión previa, más genérica, que ya estaba resuelta por el propio tribunal y que ni tan siquiera es objeto de controversia en la causa. Nadie defendía en el proceso que los partidos políticos estuvieran sometidos exclusivamente a los límites del art. $22 \mathrm{CE}$. Ese era un asunto ya superado. Lo que la actora sostenía era que, en el caso concreto de ilegalización de partidos políticos, el art. $6 \mathrm{CE}$, que nada dispone explícitamente sobre el particular, no podía servir de base para imponer, por vía legal, límites más estrictos que los expresa y limitativamente previstos en el art. 22.2 del mismo cuerpo legal. La jurisprudencia del TC suministraba abundante material para alimentar esta tesis. Ya lo hemos visto en las líneas anteriores. Pero en esta ocasión, el alto tribunal no parece estar por los matices. Prefiere el trazo grueso e insiste en argumentar como si el asunto conflictivo fuese otro, afirmando que:

«... concluir que los partidos sólo están sometidos a los límites del art. $22 \mathrm{CE}$ sería tanto como admitir que las previsiones del art. $6 \mathrm{CE}$ se agotan en el contenido de una norma no sancionada, lo que es tanto como decir, simplemente, en una proposición no normativa».

¿Por qué este interés en desenfocar la cuestión realmente planteada en el proceso?; ¿a qué razón obedece este empeño en eludir un camino argumental que el tribunal ya había desbrozado en ocasiones anteriores, para regresar a una cuestión que no era ya objeto de litigio?

\subsection{El interés en replantear la lectura conjunta y sistemática que hasta entonces había venido haciendo de los arts. 6 y 22 de la norma fundamental}

La respuesta se encuentra en la misma sentencia que comentamos. El tribunal pretende replantear sobre nuevas bases la lectura conjunta y sistemática que hasta entonces había venido haciendo de los arts. 6 y 22 de la norma fundamental. La posición prevalente que en sus sentencias anteriores había venido otorgando al art. $22 \mathrm{CE}$ en el régimen constitucional de los partidos políticos, le conducía, inexorablemente, a erigir el apartado $2 .^{\circ}$ de este precepto en la principal referencia normativa a 
tener en cuenta en todo lo relativo a su ilegalización. $\mathrm{O}$, en cualquier caso, en el muro infranqueable que insoslayablemente ha de respetar toda norma específica que pueda aprobarse en la materia; el límite impuesto por la necesidad de respetar «en todo caso, [...] los derechos fundamentales y libertades públicas» consagradas en la Constitución. Máxime si se tiene en cuenta que el art. 6 CE carece de disposición expresa alguna que haga referencia a los motivos y los procedimientos por los que puede situarse a un partido político al margen del ordenamiento jurídico.

Pero esa era, al parecer, una conclusión que el alto tribunal no quería verse obligado a alcanzar, porque no resultaba conciliable con el compromiso de «hacerlo lo mejor que supiesen» para alcanzar la «ilega...» de Batasuna. Por ello, el TC se «olvida» del camino avanzado en sus pronunciamientos anteriores y decide regresar nuevamente al inicio del itinerario argumental, planteando como central una cuestión que ya no lo es.

Aunque el tribunal comienza admitiendo - con referencia incluida a su sentencia 3/1981, de 2 de febrero-, que los partidos políticos son «una forma particular de asociación», inmediatamente incorpora a su discurso un ingrediente novedoso, al afirmar que «en ello [en lo asociativo] no se agota [...] su realidad, pues el art. 6 de la Constitución hace de ellos expresión del pluralismo político e instrumento fundamental para la participación política mediante su concurso a la formación y manifestación de la voluntad popular [...] Los partidos son, así —añade el tribunal-, unas instituciones jurídico-políticas, elementos de comunicación entre lo social y lo jurídico que hace posible la integración entre gobernantes y gobernados, ideal del sistema democrático» [F. J. 5].

Más adelante, el tribunal aporta elementos adicionales a esta caracterización institucional de los partidos políticos, precisando que la cualificación que les imprime la importancia de las funciones que tienen constitucionalmente asignadas, «...no desvirtúa la naturaleza asociativa que está en la base de los partidos, pero eleva sobre ella una realidad institucional diversa y autónoma [...] que justifica la existencia de un régimen normativo también propio, habida cuenta de la especificidad de esas funciones» [F.J. 6]. La conclusión principal que de ello se extrae, no se hace esperar. Como los partidos políticos, además de asociaciones, son, también, «instituciones jurídico-políticas»,

«La libertad característica de las asociaciones, y de la que los partidos también disfrutan, no puede ser para éstos tan omnímoda que a su amparo se desvirtúen como instrumento para la consecución de sus fines constitucionales». 
Evidentemente, esta menor libertad de la que gozan los partidos políticos, por relación a las asociaciones de régimen común, afecta de modo directo a lo dispuesto en el apartado 2. ${ }^{\circ}$ del art. $22 \mathrm{CE}$. Así lo afirma ahora el TC.

El alto tribunal había repetido, literalmente, en ocasiones precedentes que «... las previsiones contenidas en los apartados 2 -sí, sí, dice 2- y siguientes del artículo 22, en tanto que "garantía común" del derecho de asociación [STC 67/1985], son aplicables a todo tipo de asociaciones, incluidos los partidos políticos» [STC 56/1995, de 6 de marzo, f. J. 3..$^{\circ}$ ]. Y su vertiente institucional — que, recordemos, también había sido tomada en consideración en pronunciamientos anteriores- nunca había sido un obstáculo para que a los partidos les fueran plena e incondicionalmente aplicables las previsiones del art. $22 \mathrm{CE}$. Antes al contrario, el TC, incluso había llegado a imponerse sobre las alegaciones del Abogado del Estado, que pretendía un eclipse perfecto del art. 22 por parte del art. 6. Empero, ahora - justo ahora que su presidente se ha comprometido a «hacerlo lo mejor que sepa» para alcanzar un objetivo difícil de conseguir desde tales presupuestos - corrige este postulado, afirmando que, sobre lo dispuesto en este apartado 2, se impone, incluso hasta el extremo de hacerlo inaplicable, la necesidad de respetar la naturaleza jurídico-institucional de los partidos políticos. Una naturaleza de presencia exigua, casi inexistente en los pronunciamientos anteriores del tribunal pero que, en esta sentencia - precisamente en ésta - adquiere una dimensión colosal y una trascendencia crucial. Tanta como para hacer que el art. 22 CE deje de ocupar el lugar prioritario que el propio tribunal le ha venido atribuyendo de modo prácticamente sistemático en el régimen constitucional de los partidos políticos.

Según la sentencia de 12 de marzo de 2003, los límites específicos que el art. $6 \mathrm{CE}$ impone a los partidos políticos no se limitan a «la obligación de tener una estructura y un funcionamiento democráticos», sino que incluyen también, «como cuestión previa, el de respetar los cometidos que ese precepto enumera como definidores de la condición de partido político». Y esta limitación implícita, que el art. 6 CE no contempla de modo expreso, pero que alto tribunal, en una interpretación ciertamente generosa de su texto, hace derivar de las funciones que la norma suprema asigna a los partidos políticos, adquiere un peso y una virtualidad de primero orden. Antes, ya lo hemos visto, el tribunal había postulado que las normas específicas que puedan dictarse para los partidos políticos en virtud de su caracterización como asociaciones de relevancia constitucional, sólo se refieren, con arreglo a lo dispuesto en el art. $6 \mathrm{CE}$, «al respeto al orden constitucional y a su estructuración interna de carácter democrático» [STC 85/1986, f. J. 2]. 
Y había afirmado, también que tales normas «se añaden», pero «no sustituyen» a las del art. $22 \mathrm{CE}$. No sé si entre estas tesis y la que ahora defiende media un apartamiento deliberado y arbitrario de su doctrina anterior, pero la diferencia es tan real como ostensible.

Por otro lado, también lo hemos visto, el alto tribunal había defendido que las especialidades normativas dictadas para los partidos políticos al amparo del art. $6 \mathrm{CE}$, «en todo caso, deberán respetar la Constitución y, particularmente, los derechos fundamentales y libertades públicas consagrados en ella» [STC 3/1981, f. J. 1..$^{\circ}$ ], incluido, por supuesto, el derecho fundamental de asociación. Ahora, por el contrario, afirma que ese respeto no ha de producirse «en todo caso», sino sólo cuando el régimen constitucional establecido para los derechos fundamentales y libertades públicas no entre en contradicción con la naturaleza jurídico-política de los partidos políticos, o no desvirtúe a éstos «como instrumento para la consecución de sus fines constitucionales». También aquí la variación es ostensible.

El problema que esta nueva tesis plantea es el de precisar si la necesidad de respetar los «fines constitucionales» de los partidos políticos puede, no ya modular, sino anular su naturaleza asociativa, que tan enfáticamente ha proclamado el TC en numerosas sentencias, hasta el extremo de hacerles sencillamente inaplicable una norma esencial del régimen que la misma Constitución contempla para las asociaciones. Hasta ahora los «fines constitucionales» de los partidos políticos eran exactamente los mismos y el alto tribunal no había encontrado reparo en aplicarles directamente previsiones del art. $22 \mathrm{CE}$ que, sin duda alguna, pueden incidir sobre tales fines. Es más, tenía dicho que los art. 6 y 22 de la norma fundamental «deben interpretarse conjunta y sistemáticamente, sin separaciones artificiosas» [STC 56/1995, de 6 de marzo]; y había actuado de manera que la compleja naturaleza de los partidos políticos, no impidiese la aplicación a los mismos de uno sólo de los mandatos expresos que contienen estos dos preceptos. Ahora, por el contrario, propone, por primera vez, una lectura de los mismos que, de hecho, disocia radicalmente ambas normas, hasta el extremo de hacer que una de ellas devenga abiertamente inaplicable.

3.3. ¿Pueden los fines constitucionales de los partidos políticos justificar limitaciones a la libertad de éstos en ámbitos que forman parte del núcleo de la libertad de asociación?

Otra de las cuestiones que suscita la sentencia, se plantea a la hora de considerar si el necesario respeto a lo que el TC identifica como los «fines constitucionales» de los partidos políticos, pueden justificar la 
imposición a éstos de mayores límites y controles que a las asociaciones de régimen común o si, por el contrario, obliga a establecer un régimen de mayor libertad. El tribunal había postulado que «de la lectura conjunta del artículo $6 .^{\circ} \mathrm{CE}$ en conexión con el art. 22 de la misma, resulta una protección reforzada de la libertad de partidos políticos que debe entenderse afecta no sólo a la actividad de los mismos, sino a su propia creación» [STC 85/1986, de 25 de junio, F.J. 2]. Ahora, sin embargo, se apea de esta consideración y afirma que la interpretación sistemática de estos dos preceptos constitucionales, en vez de a «una protección reforzada de la libertad de partidos políticos», que afecta, entre otras, a «la actividad de los mismos», conduce a una libertad restringida, afectada por más y más severos límites y controles.

Ahora bien, ¿existe base suficiente en los fines constitucionales de los partidos políticos como para justificar limitaciones a la libertad de éstos en ámbitos que forman parte del núcleo mismo de la libertad de asociación? Veámoslo.

Según el art. $6 \mathrm{CE}$, los partidos políticos «expresan el pluralismo político, concurren a la formación y manifestación de la voluntad popular y son instrumento fundamental para la participación política». Esos son, básicamente, sus fines constitucionales. Pues bien, cualquier medida limitativa de la actuación de los partidos políticos que permitiera dejar fuera de la ley a determinadas formaciones políticas por causas distintas a las previstas en el art. 22.2 CE, parece evidente que, lejos de salvaguardar el cumplimiento de estos fines, obstaculizaría seriamente la libre «expresión del pluralismo político» —en la medida en que restringiría directamente el pluralismo- dificultaría ostensiblemente «la formación y manifestación de la voluntad popular» - ya que a una parte de la voluntad popular se le vedaría la posibilidad de manifestarse en libertad- y contribuiría decisivamente a limitar la «participación política», por cuanto que la libre participación política de los militantes, simpatizantes e incluso meros votantes del partido ilegalizado, quedaría afectada por graves restricciones. Y, por el contrario, parece igualmente evidente que la garantía de una libre expresión del «pluralismo político» y de una «participación política» sin restricciones, exigiría lo que el TC, antes de la sentencia de 12 de marzo de 2003 calificaba como de una «protección reforzada de la libertad de partidos políticos». No una limitación de ésta.

En última instancia, el argumento de los fines constitucionales nos remite a lo que en el ámbito de la Ciencia Política se ha denominado como la paradoja de la libertad: ¿Puede la defensa de la libertad justificar el liberticidio? Una paradoja que, en este caso, el Tribunal Constitucional resuelve con gran simplismo, apelando nominativamente a la 
defensa de los «fines constitucionales de los partidos políticos», pero sin ahondar en lo gravemente pernicioso que puede resultar para el cumplimiento de esos fines, la adopción de medidas públicas que constriñen el pluralismo político, alteran la voluntad popular y obstaculizan la libre participación política.

\section{4. ¿Es cierto que el constituyente sólo descartó encomendar al TC la garantía del respeto del art. 6 CE por parte de los partidos políticos?}

Si la Constitución tuviese, como ocurre con alguna otra en el ámbito comparado, una previsión que permitiera expresamente dejar a un partido político fuera del ordenamiento jurídico por razones distintas a las estrictamente penales, la cuestión que apuntamos en el epígrafe anterior, no pasaría de constituir una mera especulación politológica, sin incidencia alguna en el plano jurídico positivo. Pero la norma fundamental de 1978 nada establece a ese respecto. Como hemos visto ya en las líneas anteriores, sobre la ilegalidad de los partidos, se limita a declarar, en su art. 22.2, que son ilegales «las asociaciones que persigan fines o utilicen medios tipificados como delito» ${ }^{3}$. Pero el art. $6 \mathrm{CE}$ carece de una regla expresa y clara, equiparable a la que — por ejemploen el art. 21 de la Ley Fundamental de Bonn, declara inconstitucionales «los partidos que, por sus fines o por la conducta de sus seguidores, se propongan menoscabar o destruir el orden fundamental libre y democrático o poner en peligro la existencia de la República Federal de Alemania». Es más, en los debates constitucionales se debatió expresamente sobre la posibilidad de incorporar al art. $6 \mathrm{CE}$ una previsión similar a la del art. 21 de la Constitución alemana, pero finalmente se rechazó. Si no existe, por tanto, es porque el constituyente no lo quiso.

El TC pretende salvar este escollo, argüyendo que, el hecho de que «... el constituyente haya descartado encomendar la garantía del respeto del art. $6 \mathrm{CE}$ por parte de los partidos al Tribunal Constitucional no significa, obviamente, que se haya descartado dicha garantía en sí; únicamente que su verificación ha de corresponder al Poder Judicial ordinario en tanto no se establezca otra cosa».

${ }^{3}$ Es más. Durante la tramitación parlamentaria del proyecto de Constitución en las Cortes Generales, se suprimió del texto original de este apartado, un pasaje que declaraba, también, ilegales, las asociaciones «que atenten al orden constitucional». (Cfr. RIVAS ARJONA, Mercedes, Génesis del título I de la Constitución Española de 1978 en el seno de la ponencia, Madrid, 2002, pp. 265 a 277). La previsión que queda en el texto vigente es, pues, claramente limitativa. 
Ahora bien, ¿es seguro que el constituyente sólo rechazó la reserva de competencia al Tribunal Constitucional?; ¿o rechazó, también, la existencia de límites y controles sobre la actuación de los partidos políticos distintos a los expresamente previstos en el texto del art. 6 CE y en el apartado $2 .^{\circ}$ de su art. 22? Veámoslo.

El segundo punto de la enmienda n. ${ }^{\circ} 655$ que la Agrupación Independiente del Senado presentó contra el art. 6 del proyecto de Constitución, pretendía añadir al precepto un inciso último del siguiente tenor literal: «Corresponde al Tribunal Constitucional apreciar la constitucionalidad de los partidos».

Según expresaba literalmente la justificación de la enmienda, ésta se proponía incorporar al art $6 \mathrm{CE}$ «lo que prescribe la Constitución Alemana, que incluye el precepto al hablar de los partidos». En su defensa, el senador Ollero Gómez daba por supuesto que «el control de legalidad de actuación de los partidos corresponderá establecerlo a la Ley en los términos del Derecho de asociación y en función de los límites que a éste impone el artículo 21 [actualmente 22] de la Constitución» ${ }^{4}$. Su propuesta, por tanto, hacía referencia al establecimiento de un control de constitucionalidad de los partidos políticos. Un control distinto al de legalidad y que, a juicio, había de ser ejercido por el Tribunal Constitucional.

Sin embargo, este punto de la enmienda no llegó a votarse porque fue retirado por el propio senador Ollero, quien se reservó «el volver a hablar del tema al discutir el artículo 159 del proyecto constitucional». Resulta interesante anotar, no obstante, que el anuncio de retirada se produjo inmediatamente después de que el senador Sainz de Varanda, portavoz del grupo socialista en la cámara alta, expresase su posición contraria a la admisión de esta enmienda, en base a los siguientes argumentos:

«Señalamos a los señores senadores la importancia que precisamente tiene este texto, porque significa que podría poner en tela de juicio, para que la jurisprudencia decidiera la existencia de una gran cantidad de partidos políticos cuyo ideario no coincide en absoluto con los preceptos de la Constitución.

Por tanto, entendemos que se trata de una limitación muy grave al derecho de asociación política y que lo que se menciona en la fundamentación, que es el precedente de la Constitución alemana de Bonn, no parece que sea el caso, porque además de las circunstancias especialísimas que se daban en la República Federal Alemana cuando se aprobó la Ley Fundamental de Bonn, entendemos que, con arreglo al sistema de partidos

${ }^{4}$ Diario de Sesiones del Senado, núm. 41 de 22 de agosto de 1978, p. 3097. 
políticos que en España tenemos vigente, sería un retroceso, frente a la situación actual, aprobar este texto [...] de ninguna manera [entendemos] que corresponda al Tribunal Constitucional decidir la constitucionalidad de los partidos, porque la jurisprudencia nos podría llevar a la desaparición de la mayor parte de los partidos democráticos españoles» ${ }^{5}$.

Interesa igualmente anotar que, los portavoces que tomaron la palabra después de comunicada la intención de retirar este punto de la enmienda, expresaron, también, una disposición claramente contraria a su aceptación. González Seara, portavoz del grupo parlamentario de UCD observó que «no estábamos de acuerdo» con el punto retirado aunque, como éste no formaba ya parte del debate, se ahorró la exposición de las razones en las que fundaba su desacuerdo. Algo más explícito, Villar Arregui calificó la enmienda de «restrictiva».

Del tenor de estas intervenciones parece claro que lo que los constituyentes rechazaban no era tanto la atribución al TC de la competencia para ejercer un control constitucionalidad de los partidos políticos distinto al de legalidad previsto en el art. 22.2 CE — que era la propuesta del senador Ollero - cuanto la existencia misma de un control de constitucionalidad sobre los mismos. En otro caso, carecerían de sentido las referencias a su carácter «restrictivo»o al «retroceso» que su aprobación pudiera suponer en relación con el sistema vigente de partidos políticos. Porque lo «restrictivo» de la enmienda, lo podía poner en peligro la existencia «de una gran cantidad de partidos políticos cuyo ideario no coincide en absoluto con los preceptos de la Constitución», en ningún caso podría ser la atribución de la competencia al Tribunal Constitucional, sino la implantación misma de un cauce extrapenal de control de los partidos políticos. Esta es una conclusión que se extrae claramente y sin excesiva violencia, de la lectura de los antecedentes parlamentarios de la norma normarum.

Pero el TC, que tantas veces y tan decisivamente ha recurrido a los trabajos parlamentarios de la Constitución para definir el alcance y contenido de algunos de sus preceptos, no siente, en este caso, la necesidad de atender a los antecedentes de la norma para descubrir la voluntad del constituyente. Rechaza a limine la alegación de la parte actora, sin molestarse en averiguar hasta qué punto la inexistencia en el art. $6 \mathrm{CE}$ de una norma como la del art. 21 de la Ley Fundamental de Bonn, refleja la voluntad del constituyente de excluir la posibilidad de que los partidos políticos puedan ser ilegalizados por causas distintas a las previstas en el art. 22.2 CE.

5 Ibidem, p. 3098. 
Por lo demás, que durante la época en la que tuvieron lugar los debates constitucionales, primaba, en las Cortes Generales, la idea de no someter a los partidos políticos a más controles que aquellos de carácter penal que pudieran derivarse del art. 22.2 CE, es buena muestra el debate que se produjo con motivo de la aprobación de la Ley 54/1978, de 4 de diciembre, de Partidos Políticos. En la sesión plenaria del Congreso de los diputados que puso fin a su tramitación, el portavoz del grupo mayoritario afirmó hasta tres veces que el régimen de control que el nuevo texto establecía en relación con los partidos políticos, se limitaba al terreno estrictamente penal. La Ley, aseguraba Meilán Gil al inicio de su intervención, preveía un control estricto «exclusivamente judicial, cuyos límites están en las fronteras del Derecho Penal». Al aludir a las causas legales que legitimaban las intervenciones públicas de control sobre las organizaciones políticas, afirmaba nuevamente que, en el proyecto, «Los motivos para ello están también tasados. Es la ilicitud penal y no cualquier otra ilicitud considerada genéricamente. De esta manera - añadía - se van a resolver problemas que se habían planteado en el pasado, que dieron lugar a sentencias famosas como la de 1 de abril de 1977, que me figuro particularmente conocida de algún Grupo Parlamentario que se sienta en esta Cámara» ${ }^{6}$. Finalmente, al reseñar las aportaciones que los diferentes grupos parlamentarios habían efectuado para mejorar el texto original del proyecto, destacaba las realizadas de cara a «la fijación y concreción de qué ilicitud se trata: de la ilicitud penal, no de una contravención genérica del Derecho» ${ }^{7}$.

${ }^{6}$ La referencia que el portavoz del grupo mayoritario hace a la sentencia de 1 de abril de 1977 (Ar. 4635) tiene su interés a efectos de delimitar el propósito de excluir de los supuestos de ilegalización toda ilicitud distinta a la estrictamente penal. En efecto, la sentencia en cuestión, dictada por la sala 4. ${ }^{\mathrm{a}}$ del alto tribunal, resuelve el procedimiento iniciado por el Ministerio de la Gobernación en relación con la eventual ilicitud penal del Partido Comunista de España, cuya inscripción se había solicitado en el Registro de Asociaciones Políticas. El caso no hubiese revestido especial significación si no hubiera sido porque, apreciada, por la Administración, la posible existencia de elementos delictivos en la organización política cuya inscripción se recababa, el expediente hubiese sido remitido a los tribunales de la jurisdicción contencioso-administrativa y no a los del orden jurisdiccional penal. Evidentemente, la sala 4 . $^{\text {a }}$ declara su falta de jurisdicción para conocer de las actuaciones y, además, anula el acto del Ministerio de Gobernación «en el particular extremo del mismo que ordena la remisión del expediente administrativo a este Tribunal, acordando por tanto su devolución a dicho Ministerio». Pero más allá de lo acaecido, el hecho pone de manifiesto hasta qué punto existía una confusión en torno a los motivos que podían justificar la exclusión legal de un determinado partido político y el procedimiento que había de seguirse para ello. Para Meilán, la nueva Ley ponía fin a esta confusión, dejando claro que sólo la ilicitud penal podía servir de base para ello.

7 Diario de Sesiones del Congreso de los Diputados, núm. 94, de 21 de junio de 1978, pp. 3540 y 3541 . 


\subsection{El fraude de los principios del derecho punitivo}

En fin, la tesis del alto tribunal plantea otro problema de muy hondo calado. Si los supuestos de hecho a los que la LOPP anuda la posible ilegalización de un partido político, describieran situaciones y conductas que nada tienen que ver con aquellas para las que la legislación penal contempla idéntica consecuencia, la cuestión jurídica se reduciría, como hemos visto, a resolver si el juego combinado de los arts. 6 y 22 CE permite la ilegalización de un partido político por causas distintas a la de la persecución de fines o la utilización de medios tipificados como delito.

Sin embargo, no es ese el caso que nos ocupa. La LOPP ha sido redactada de tal manera que, entre su articulado y el del Código Penal, se produce un claro solapamiento a la hora de configurar los supuestos en base a los cuales puede decretarse la ilegalización de un partido político. Esta fue una circunstancia que se denunció infructuosamente durante la tramitación parlamentaria de la LOPP. Ahora, lo reconoce expresamente el propio TC cuando admite que algunas de las conductas recogidas en el art. 9 de la norma impugnada «pueden tener encaje en preceptos como los arts. 515, 576 y 578 del Código Penal». La coincidencia «entre el art. 9.2 y la Ley Penal no es absoluta», precisa el tribunal, pero existe, y encierra, además, una importancia notable.

Con este solapamiento, la LOPP hace que unas conductas idénticas a las tipificadas como delictivas en el Código Penal, puedan dar lugar a unas mismas consecuencias jurídicas - la ilegalización de un partido político-, pero obviando las garantías procesales y materiales que el Derecho punitivo - básicamente condensado en los artículos 24 y $25 \mathrm{CE}$ exige respetar. En esencia, pues, la LOPP consuma un fraude a estos principios del Derecho punitivo. Un fraude, ciertamente grave, que el TC pasa por alto con absoluta indiferencia.

\section{Observación final}

Es cosa conocida que, aun cuando ambos se tramitan ante el mismo órgano judicial, el recurso de inconstitucionalidad y el de amparo, constituyen instrumentos procesales diferentes, concebidos y regulados de modo distinto y que, en consecuencia, reclaman del TC pronunciamientos de naturaleza muy diversa. Tampoco ignoramos que, mientras las tres sentencias dictadas sobre la materia con anterioridad a la STC 48/2003, de 12 de marzo, lo han sido en el marco de otros tantos recursos de amparo, esta última pone fin a un procedimiento iniciado con motivo de 
un recurso de inconstitucionalidad. No se nos oculta, por ello que, con toda probabilidad, habrá quien pretenda atribuir a esta circunstancia el repentino viraje que en las líneas anteriores hemos puesto de manifiesto en la actuación del alto tribunal.

Empero, parece claro que, por sí solo, este dato no puede justificar una alteración tan radical de los postulados defendidos con anterioridad por el TC. La exégesis de la Constitución no puede variar al albur de lo que, en cada caso se somete a su conocimiento o del cauce procesal elegido para ello. El tribunal nunca ha disociado formalmente sus resoluciones en función del tipo de recurso en el que hayan sido dictados. Antes al contrario, puede decirse que, en general, ha procurado integrarlos en un mismo hilo argumental. De hecho, se puede comprobar sin excesiva dificultad que, cuando invoca sus pronunciamientos anteriores sobre una determinada materia, el alto tribunal acostumbra a incluir en la cita, indistintamente, sentencias y autos dictados en cualquier tipo de los procedimiento que entran en su ámbito de competencia: Recursos de inconstitucionalidad, recursos de amparo y conflictos competenciales. La misma sentencia 48/2003, de 12 de marzo, constituye un claro ejemplo de ello.

Así, pues, el hecho de que la sentencia que comentamos haya sido dictada en el seno de un tipo procesal distinto al que ha servido de marco a las anteriores sentencias sobre la materia, no puede justificar un viraje doctrinal tan drástico. La única circunstancia auténticamente diferencial que concurría en este caso, era el compromiso del presidente del tribunal y ponente del caso, de «hacerlo lo mejor que supiera» para alcanzar un determinado objetivo; un objetivo para cuya consecución, los pronunciamientos anteriores del tribunal no constituían precisamente una ayuda. Una circunstancia que invita al jurista a meditar sobre el sentido de la sagaz conversación entre Alicia y Humpty Dumpty con la que hemos dado inicio a este trabajo. 